\title{
Analysis of Public leisure space rest seat design elements
}

\author{
Zong Yan \\ Changchun School of Architecture \\ Changchun, China
}

\begin{abstract}
This paper mainly seven aspects of public leisure space to rest seat design elements were analyzed by discussing public leisure space to rest seat culture, layout, climate, materials, accessibility, natural environment, and other factors discussed form.
\end{abstract}

\section{Keywords- Rest seats; elements}

\section{CULTURAL CONNOTATIONS}

As a key part of urban home, the seat is a public symbol, a cultural symbol, bearing the life in which people's memories. Different cities, different age seat design requirements are different, so the formation of a diversity of urban style. Therefore, when the seat must be designed with local specialties, respect for traditional culture, so that the city retains its original unique character, cultural heritage and promote the city, thus ensuring the quality of urban public space. Let the city while maintaining the historic charm of the original premise, continue to mark the city's unique heritage and carried forward from generation to generation.

In the public space, not all people are like the same type of public space, so designers according to their characteristics of different groups, targeted design. Can follow the age, gender, occupation and other criteria, a comprehensive analysis of the use of the crowd, so as to clearly understand the characteristics of different groups and local use when designing important consideration.

\section{LAYOUT DISTRIBUTION}

Seats should rest primarily on the location of pedestrian flow, no less anti-people activities to be placed or not placed, concrete can be divided into the following Discussion:

(1) seat beside the road does not affect the normal set of first crowd flow, and the flow line is, to maintain an appropriate distance, so as not to discourage people from walking. In addition, we can not too far from the sidewalk, so that will reduce the usage of seat.

(2) Do not place alone as the rest of the seat, but the surrounding environment and facilities together with a reasonable match. Such as trees, newsstands, street lamps, telephone booths and so on.

(3) According to Sam's personal space theory, when the seat is set to reduce or avoid face to face setting, as a stranger to take the time to feel anxious or uncomfortable. When the case had to face during the design, to make the seat was $90^{\circ}$ to $120^{\circ}$ angle, because studies show that the probability of the people of this angle is great to talk with each other, to avoid embarrassing incidents occur.
(4) Set the seat to let users have a choice of space, can not be unified set in the same environment, to diversity, such as the sun, in the shade, leeward Department. But this only applies to those who can move the seat.

\section{DESIGNED TO TACKLE CLIMATE CHANGE}

Since climate change has some effect on the seat material, and therefore, usually on the seat for reprocessing, the surface of the seat is very important for processing, the process is indispensable, it can enhance the corrosion resistance of the seat, moth the role of food. In addition to painting techniques seats, it also can choose some other solutions, increasing its durability, for example, can use galvanized or plated steel; or wood to wood stain instead of paint; or directly to do with concrete seats. So as to achieve an appropriate response to climate change has brought corrosion.

\section{THE USE OF MATERIALS}

Seat material requires rigorous selection, these materials must withstand wind and rain erosion, air pollution, as well as vandalism. For these features, we add to the selection. Many types of materials, there are materials of wood, stone, concrete, plastic and some other column, we need to be selected.

\section{A. User-friendly design wooden seating facilities}

Seat made of wood feels good, they have a friendly appearance, so the use of wooden chairs seem higher than stone benches. But wood processing strength, durability and relatively poor. If these wood preservative treatment, their durability will increase, therefore, the replacement cost is not too high. With the development of society, the wood adhesive technology and bending technology has been greatly improved, the seat becomes a wide range of forms. These wood products, mainly to observe the color of wood, workmanship, quality from the point of view of human vision. According to furniture design, including visual, auditory, tactile full-shift, forming a richer sensory system. Wood texture better, because they go through a good deal. When the wood products used in public places, due to the relatively large outdoor climate change, they need to go through the wind and rain, and some man-made damage, it will affect their durability, so we have to choose some of the more economical, and durability compare good wood. If the chair is mainly used some wooden slats to be made, it is relatively easy to bad, I often need to replace these slats. At 
the time of production of these seats should produce more appropriate for future maintenance work.

Metal seats are designed to be more humane point. Features metal is durable, they are more style, can be made into a variety of. But they are not very good impression. Cast iron, with a heavy sense of performance and durability, and their relatively high plasticity, metal materials, stainless steel and aluminum, as relatively high conductivity, outdoor seating made less humane. Because now the stamping process evolving, can be made into a network structure, so that these metals will be greatly improved heat dissipation can be used to make the seat.

\section{B. the design of the plastic seat}

As the plastic material is a high plasticity, they are easy to process, and various colors, are generally applicable to the seat surface and made of some other material feet. But plastic is easier to corrode, and their strength and durability are very poor, and this will cause a lot of trouble. In order to change the properties of these materials, they can be made of composite material, such that the strength of the material is greatly improved. For a variety of occasions to rest.

\section{ACCESSIBLE DESIGN}

Rest seat design to fully consider the normal physiological activity of disability and who have varying degrees of decline (such as the disabled, elderly, children) people's needs and create a loving and caring, effective protection of human security, convenience, comfort the environment, the response to the behavior of human consciousness movement carried out a detailed study on the basis of some proposed optimization design for a variety of environments and is committed to a variety of objects, so it can solve many problems for consumers, for everyday problems encountered in daily life, the designer should lead to attention, to provide users with convenient, this is the basic idea of the rest of the seat.

Rest seat design concern, attention to the special needs of the disabled, the elderly.

\section{NATURAL ENVIRONMENTAL FACTORS}

Different geographical environment, its natural climate and natural resources are different, the difference of the natural environment of public leisure space to rest seat design influence is very large, these factors largely determine the shape of the rest of the seat structure, material selection functional use and the use of methods. Therefore, in the beginning of the rest seat design to conduct a detailed investigation and analysis. Must understand the area of the seat temperature, humidity, precipitation, sunshine and so on. For example, in the north, the weather is cold, dry winters and longer, more snow, so the environment and facilities should be designed to give more consideration to seat availability, pay attention to cold, heat, frost, so the choice of materials should be used sparingly steel, iron, aluminum and other metal materials cold stiff, as many materials such as wood, plastic or glass, etc. have a warm feeling with; another eye-catching bright colors should be chosen to create a spring atmosphere. In the south, the climate is hot, humid, rainy, seat pay attention to sun, moisture, corrosion, in the shape of the seat should pay attention to ventilation, shading and rain. Thus, the rest of the seat should be designed to take into account the surrounding natural environment, so as to achieve the harmony of nature and man.

\section{FORM FACTOR ANALYSIS}

Form factor seat includes morphological features and color features. Product space shape and style of art form that is the sum of the shape and posture. Form design personalized design for the seat is particularly important, shape, scale, proportion of different seats, bringing people of different psychological feelings, designers should design a suitable shape modeling based on the face of people and the environment to meet the needs of the people of the physiological and psychological.

Color is the most sensitive design elements, the seat design also plays an important role. Different colors will bring people of different psychological feeling, he can directly affect the environment and people's emotional atmosphere. For example, you can create a bright, bright colors, fun, pleasant atmosphere, and deep dark colors can create depression, boredom, oppressive atmosphere. In addition, the color also has a decorative and recognition, you can play guidelines, hints, warning effect. For example, the color yellow warning signs are often used.

\section{CONCLUSION}

In terms of color, people always prefer natural materials and elegant color, Bright color, natural materials seat intimacy but people have to be designed to seat color depending on the environment, people can find a seat to meet as soon as possible requirements, but also the seat and the surrounding environment rather than abrupt. Specifically, if more hidden location, you need to use a high purity and brightness of color, if the position clear, then, on the use of low brightness and color purity.

11] cold red livable winter city environmental studies re Harbin: China Building Industry Press, 2009.

[2] China Building Technology Development Center of foreign public leisure space buildings, unknown.

[3] Wang Baoshan, Guo Xiaoming translation, labeled universal design environment, China Building Industry Press, 2004

[4] Ma Daoming, rational city - eco-city regulation, Southeast University Press, 1984.

[5] Shishu Wen edited, color design of the built environment, Beijing, China Building Industry Press, 2002. 